\title{
Selection for chloroquine-sensitive Plasmodium falciparum by wild Anopheles arabiensis in Southern Zambia
}

\author{
Sungano Mharakurwa ${ }^{1,2^{*}}$, Mavis Sialumano ${ }^{1}$, Kun Liu' ${ }^{2}$, Alan Scott ${ }^{2}$ and Philip Thuma ${ }^{1,2}$
}

\begin{abstract}
Background: The emergence of parasite drug resistance, especially Plasmodium falciparum, persists as a major obstacle for malaria control and elimination. To develop effective public health containment strategies, a clear understanding of factors that govern the emergence and spread of resistant parasites in the field is important. The current study documents selection for chloroquine-sensitive malaria parasites by wild Anopheles arabiensis in southern Zambia.
\end{abstract}

Methods: In a 2,000-sq km region, mosquitoes were collected from human sleeping rooms using pyrethrum spray catches during the 2006 malaria transmission season. After morphological examination and molecular confirmation, vector mosquitoes were dissected to separate head and thorax from the abdominal section, followed by PCR screening for $P$. falciparum infection. Human residents of all ages were tested for $P$. falciparum parasitaemia by microscopy and PCR. Plasmodium falciparum infections were genotyped at the chloroquine resistance-conferring amino acid codon 76 of the PFCRT gene, using PCR and restriction enzyme digestion.

Results: In the human population there was nearly 90\% prevalence of the chloroquine-resistant PfCRT K76T mutant, with no significant differences in polymorphism among smear-positive and smear-negative (submicroscopic) infections $(p=0.323, n=128)$. However, infections in both abdominal and salivary gland phases of the An. arabiensis vector exhibited wild type K76-bearing parasites with up to 9X higher odds (OR (95\% Cl): 9 (3.7-20.2), $p<0.0005$, $\mathrm{n}=125)$, despite having been acquired from humans within a few weeks.

Conclusions: Anopheles arabiensis selects for wild-type K76-bearing P. falciparum during both abdominal and salivary gland phases of parasite development. The rapid vectorial selection, also recently seen with antifolate resistance, is evidence for parasite fitness cost in the mosquito, and may underpin regional heterogeneity in the emergence, spread and waning of drug resistance. Understanding the nature and direction of vector selection could be instrumental for rational curtailment of the spread of drug resistance in integrated malaria control and elimination programmes.

\section{Background}

The emergence and spread of parasite drug resistance, especially Plasmodium falciparum, continues to pose a major obstacle for malaria control and elimination [1,2]. Plasmodium falciparum has repeatedly proven ability for mounting resistance to any anti-malarial drug regimen upon wider use, including current ones [2-7]. To avert

\footnotetext{
* Correspondence: sungano.mharakurwa@macharesearch.org

'The Malaria Institute at Macha, PO Box 630166, Choma, Zambia ${ }^{2}$ Department of Molecular Microbiology \& Immunology, Johns Hopkins Malaria Research Institute, Johns Hopkins Bloomberg School of Public Health, 615 N Wolfe Street, Baltimore, MD 21205, USA
}

potential resurgence owing to treatments that are no longer effective, not only are new anti-malarials needed, but also public health strategies that will minimize or delay drug resistance escalation $[8,9]$.

There are only a few strategies that have been rationalized and adopted to date, namely, avoidance of sub-therapeutic doses $[10,11]$, combination therapy, especially with artemisinin and its derivatives [12], and focused screening and treatment, which was recently started in Southeast Asia in an effort to stem the global spread of emerging $P$. falciparum tolerance to artemisinin [13]. So far P. falciparum evidently evades all these approaches $[14,15]$.

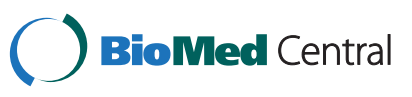

(c) 2013 Mharakurwa et al.; licensee BioMed Central Ltd. This is an Open Access article distributed under the terms of the Creative Commons Attribution License (http://creativecommons.org/licenses/by/2.0), which permits unrestricted use, distribution, and reproduction in any medium, provided the original work is properly cited. The Creative Commons Public Domain Dedication waiver (http://creativecommons.org/publicdomain/zero/1.0/) applies to the data made available in this article, unless otherwise stated. 
To develop effective strategies for containment of drug resistance, an understanding of the epidemiological factors that govern the emergence and spread of resistant parasites in the field is paramount. Theoretical arguments [12,16], although sometimes conflicting [13,14], and a review [15], have posited an association between malaria transmission control and levels of P. falciparum drug resistance. Meanwhile, field studies have shown an unexpected but decisive association between mosquito control and the prevalence of $P$. falciparum drug resistance $[17,18]$. The prevalence of $P$. falciparum dihydrofolate reductase (DHFR) wild-type (antifolate drug-sensitive) alleles increased in Tanzania when insecticide-treated nets (ITNs) were implemented [16]. In an area of Zimbabwe, the introduction of indoor residual insecticide spraying (IRS) was associated with a four-fold reduction in the odds of chloroquine therapeutic failure after four years [17], despite concurrent drug pressure. Cessation of the IRS was linked to a four-fold rebound in odds of chloroquine resistance after another subsequent four years [17]. In contrast, Shah et al. found no significant relationship between sustained ITN use and the prevalence of chloroquine or antifolate drug resistance in western Kenya [19].

What remains unclear is why drug resistance associates with mosquito control in some areas but not others. Similarly, why does the removal of drug selection pressure result in decisive re-emergence of sensitive parasites in some areas [20-25] and yet other locations show slow recovery or fixation [26-29]? A recent study suggests that mosquito vectors may play a role in determining field levels of drug-resistant P. falciparum [30] and thus constitute an additional governing factor in drug resistance epidemiology. This means that mosquito control may influence parasite drug resistance indirectly, through impact on vector species that select on drug resistance polymorphism. Highly contrasting $P$. falciparum antifolate drug resistance polymorphisms were found in human and mosquito hosts that seemed to suggest strong selection against pyrimethamine resistance mutants by the Anopheles arabiensis vector [30]. The current study documents An. arabiensis selection on the chloroquine resistance-conferring polymorphism of the $P$. falciparum chloroquine resistance transporter (PfCRT) gene[31].

\section{Methods}

\section{Study area and population}

The study was based in a 2,000-sq $\mathrm{km}$ vicinity of the Malaria Institute at Macha (MIAM) and Macha Mission Hospital, a 208-bed, rural, district-level hospital in Southern Province of Zambia. The area has an altitude of 9001,000 $\mathrm{m}$ above sea level and historically experienced hyperendemic malaria, which is transitioning to hypoendemicity following scale-up of ITN and artemisinin combination therapy (ACT) interventions since 2004.
The resident population is approximately 160,000 and comprises primarily subsistence farmers of the Batonga communities. As with the rest of Zambia, chloroquine, the former first-line treatment for malaria for many years, was suspended from use in 2003 and replaced with artemether-lumefantrine.

\section{Design}

The study was a cross-sectional survey. Plasmodium falciparum chloroquine resistance polymorphism was determined in humans and local An. arabiensis vector mosquitoes.

\section{Parasite DNA sample collection Mosquito phase}

Following prior appointment with the resident communities, whole mosquitoes were collected from human sleeping rooms by pyrethrum spray catches in the morning from 06.00-10.00 [30].

\section{Human phase}

Through prior arrangement, willing community residents of all ages assembled at existing central meeting points, during the afternoons of the same day as pyrethrum spray catches, for malaria screening by microscopy as previously described [30]. Parasite DNA samples were simultaneously collected as filter paper dry blood spots (DBS) from the same finger-prick used to prepare microscopy blood films.

\section{Parasite DNA extraction Mosquitoes phase}

The mosquitoes collected from sleeping rooms of the resident population were identified morphologically, with confirmation by sibling species complex differentiation PCR for Anopheles gambiae s.l. and Anopheles funestus s.l. as previously described [30,32]. Parasite DNA was extracted separately from the mosquito abdominal and salivary gland phase using a modified chelex protocol [33].

\section{Human phase}

Parasite DNA was extracted from DBS samples using the regular chelex method [34].

\section{Assays for Plasmodium falciparum drug resistance alleles} Plasmodium falciparum infections were genotyped for the chloroquine resistance-conferring K76T mutation in the PfCRT gene using nested PCR and allele-specific restriction enzyme digestion $[31,35]$.

\section{Ethical considerations}

The study was approved by the Johns Hopkins IRB and the University Of Zambia Research Ethics Committee (UNZAREC) as part of an ongoing geographical and demographic reconnaissance study of malaria. 


\section{Results}

Prevalence PfCRT K76T in human malaria infections

From a total of 2,278 residents screened, 128 P. falciparum infections were genotyped for PfCRT-76 polymorphism (Figure 1). In the humans, the prevalence of chloroquineresistant K76T-bearing P. falciparum was virtually $90 \%$. No significant differences in the K76T single nucleotide polymorphism (SNP) were observed among microscopypositive and microscopy-negative (submicroscopic) human malaria infections (Figure 1).

\section{Prevalence PfCRT K76T in mosquito malaria infections}

Of 753 vector mosquitoes captured from human sleeping rooms, 745 (99\%) were An. arabiensis, the remaining 8 (1\%) being An. funestus. Despite having been acquired from humans within the previous ten days, $A n$. arabiensis mosquito abdominal infections exhibited more than twice the proportion of wild-type (K76-bearing) $P$. falciparum that is sensitive to chloroquine (Figure 1). The proportion of K76-bearing P. falciparum was more than five times higher in the mosquito salivary gland phase than in humans, despite having been acquired from the latter within the previous few weeks defining the natural life span of a mosquito in the wild (Figure 1). Only one of the eight An. funestus was found positive for $P$. falciparum infection, which was in the abdomen and bore PfCRT $76 \mathrm{~T}$.

\section{Discussion}

Data from the present study point to a strong natural selection for chloroquine-sensitive $P$. falciparum by An. arabiensis during both the abdominal and salivary gland phases of development. Within the short mosquito phase of the parasite, lasting only a few weeks, $P$. falciparum infections in salivary gland stage exhibited four-fold and nine-fold higher odds of chloroquine-sensitive parasites than abdominal and human phase infections, respectively. Thus, there appears to be two distinct and sequential stages of this "vectorial selection" for wild type P. falciparum in the mosquito host.

The observed data concur with earlier findings showing $A n$. arabiensis selection against pyrimethamine resistance mutants [30] in the same area. Owing to low numbers for An. funestus, it could not be determined whether this vector exerts similar selection as seen in An. arabiensis. Nonetheless, in a Tanzanian study by Temu et al. [36], An. arabiensis appeared to consistently carry a lower proportion of PfCRT 76 T mutants than both An. funestus and An. gambiae s.s.

The mechanistic basis for the "vectorial selection" on drug resistance polymorphism is not clear from a cross-sectional field survey. However, fitness cost is a possible explanation. Drug resistance mutations, including PfCRT, are known to bestow altered biological fitness on the parasite, which has so far been reported

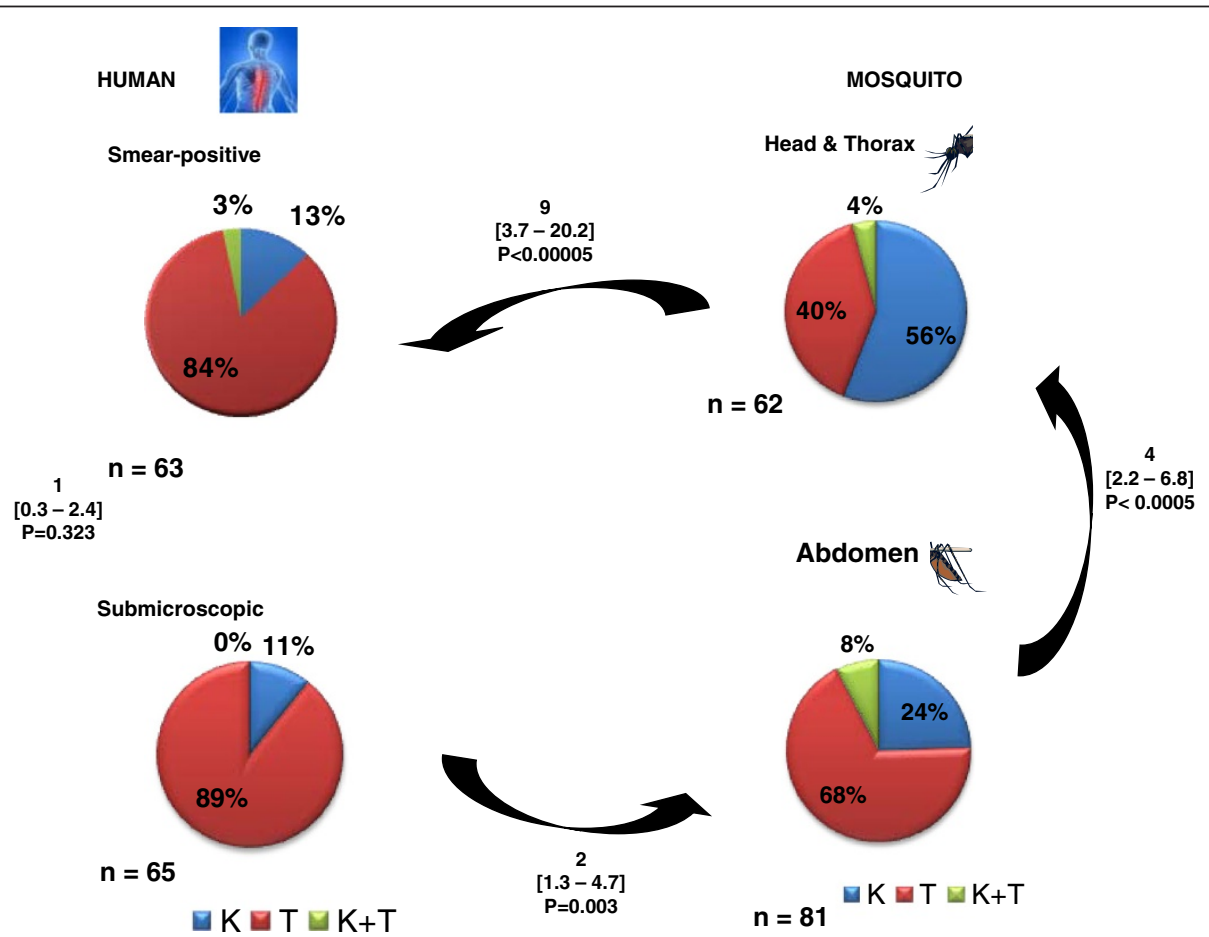

Figure 1 PfCRT K76T polymorphism in human and mosquito phases of infection (interspersing numbers are odds ratios $(95 \% \mathrm{CI})$ ). 
in vitro, in humans [37-42] and more recently in mosquitoes [30]. Mosquitoes have been shown to mount effective immune clearance of malarial infection, hence bottlenecking parasites during mid-gut as well as salivary gland invasion $[43,44]$. Presumably, less fit mutated parasites are largely eliminated during these successive survival-limiting stages of parasite development in the mosquito. Mosquitoes are also the definitive host where parasite genetic recombination takes place that can break down resistance haplotypes.

On the other hand, mid-gut microbiota have been reported to have direct anti-malarial properties [45-47] that could possibly impose selection on $P$. falciparum in the mosquito. Differences in gametocytogenesis $[48,49]$ between mutated and wild type parasites may be another possible reason for selective parasite survival in the vector. However, both the mid-gut microbiota and gametocytogenesis would not explain the strong selection for K76 observed between abdominal and salivary gland phases of the parasite, which was similarly observed with antifolate resistance polymorphism [30]. Thus, a general fitness cost of resistance in the mosquito appears the most reasonable hypothesis.

Irrespective of the underlying mechanisms, the results observed in the present study appear to lend further evidence that vector mosquitoes may play an important role in drug resistance epidemiology [30]. It is hypothesized that the vectorial selection contributes to recovery of chloroquine-sensitive malaria parasites following withdrawal of drug use, as observed initially in Hainan Province of China [50] and subsequently Malawi [23,24] and other areas, including the site of the current study (Sialumano et al. in prep). Such natural vectorial selection is in concert with observations by Laufer et al. that reemerging chloroquine-sensitive $P$. falciparum are preexisting diverse parasites that survived the chloroquine era, rather than a new invading strain [51]. Vectorial selection on parasite drug resistance polymorphisms would also appear to explain the field observations of association between mosquito control and prevalence of $P$. falciparum drug resistance $[17,18]$, and may underpin regional differences in susceptibility to the emergence and spread of drug resistance, depending on relative survival of mutated parasites in the local vector species. To better understand the possible role of the vector mosquitoes in anti-malarial drug resistance epidemiology, more field studies and controlled laboratory experiments are needed.

\section{Conclusions}

Anopheles arabiensis selects for wild type (K76-bearing) $P$. falciparum during the abdominal and salivary gland phases of parasite development. The vectorial selection is evidence for $P$. falciparum drug resistance fitness cost in the mosquito and may underlie regional heterogeneity in the emergence, spread and waning of drug resistance. Understanding the nature and direction of vector selection could be instrumental for rational curtailment of the spread of drug resistance in integrated malaria control and elimination programmes.

\section{Competing interests}

The authors declare that they have no competing interests.

\section{Authors' contributions}

SM was the principal investigator who initiated, designed and ran the study, followed by data analysis and writing of the manuscript. MS performed laboratory assays and reviewed the manuscript. KL reviewed and contributed to the manuscript. AS provided essential technical input and reviewed the manuscript. PT was the overall advisor and reviewed the manuscript. All authors read and approved the final manuscript.

\section{Acknowledgements}

The research team is grateful to the chiefs, headmen and communities of Macha, Muchila, Mapanza and Chikanta areas for their support and participation in the study. Harry Hamapumbu assisted tremendously in coordination of field research activities and staff supervision. The study was supported by the Johns Hopkins Malaria Research Institute pilot grant system and the Southern Africa International Centres of Excellence for Malaria Research programme under NIH/NIAID grant 1U19AI089680.

Received: 4 October 2013 Accepted: 17 December 2013

Published: 19 December 2013

\section{References}

1. Mita T, Tanabe K: Evolution of Plasmodium falciparum drug resistance: implications for the development and containment of artemisinin resistance. Jpn J Infect Dis 2012, 65:465-475.

2. Amaratunga C, Sreng S, Suon S, Phelps ES, Stepniewska K, Lim P, Zhou C, Mao S, Anderson JM, Lindegardh N, Jiang H, Song J, Su XZ, White NJ, Dondorp AM, Anderson TJ, Fay MP, Mu J, Duong S, Fairhurst RM: Artemisinin-resistant Plasmodium falciparum in Pursat province, western Cambodia: a parasite clearance rate study. Lancet Infect Dis 2012, 12:851-858

3. Wongsrichanalai C: Artemisinin resistance or artemisinin-based combination therapy resistance? Lancet Infect Dis 2013, 13:114-115.

4. Carrara VI, Lwin KM, Phyo AP, Ashley E, Wiladphaingern J, Sriprawat K, Rijken M, Boel M, McGready R, Proux S, Chu C, Singhasivanon P, White N, Nosten F: Malaria burden and artemisinin resistance in the mobile and migrant population on the Thai-Myanmar border, 1999-2011: an observational study. PLoS Med 2013, 10:e1001398.

5. Satimai W, Sudathip P, Vijaykadga S, Khamsiriwatchara A, Sawang S, Potithavoranan T, Sangvichean A, Delacollette C, Singhasivanon P, Kaewkungwal J, Lawpoolsri S: Artemisinin resistance containment project in Thailand. II: Responses to mefloquine-artesunate combination therapy among falciparum malaria patients in provinces bordering Cambodia. Malar J 2012, 11:300

6. Fairhurst RM, Nayyar GM, Breman JG, Hallett R, Vennerstrom JL, Duong S, Ringwald P, Wellems TE, Plowe CV, Dondorp AM: Artemisinin-resistant malaria: research challenges, opportunities, and public health implications. Am J Trop Med Hyg 2012, 87:231-241.

7. Breman JG: Resistance to artemisinin-based combination therapy. Lancet Infect Dis 2012, 12:820-822.

8. White NJ, Olliaro PL: Strategies for the prevention of antimalarial drug resistance: Rationale for combination chemotherapy for malaria. Parasitol Today 1996, 12:399-401.

9. Laufer MK, Djimde AA, Plowe CV: Monitoring and deterring drug-resistant malaria in the era of combination therapy. Am J Trop Med Hyg 2007, 77:160-169

10. WHO MPAC, Secretariat: Malaria Policy Advisory Committee to the WHO conclusions and recommendations of September 2012 meeting. Malar J 2012, 11:424

11. Price RN, Nosten F: Drug resistant falciparum malaria: clinical consequences and strategies for prevention. Drug Resist Updat 2001, 4:187-196. 
12. WHO: WHO Briefing on Malaria Treatment Guidelines and Artemisinin Monotherapies. Geneva: World Health Organization; 2006.

13. Hoyer S, Nguon S, Kim S, Habib N, Khim N, Sum S, Christophel EM, Bjorge S, Thomson A, Kheng S, Chea N, Yok S, Top S, Ros S, Sophal U, Thompson MM, Mellor S, Ariey F, Witkowski B, Yeang C, Yeung S, Duong S, Newman RD, Menard D: Focused Screening and Treatment (FSAT): a PCR-based strategy to detect malaria parasite carriers and contain drug resistant P. falciparum, Pailin, Cambodia. PLoS One 2012, 7:e45797.

14. Kyaw MP, Nyunt MH, Chit K, Aye MM, Aye KH, Aye MM, Lindegardh N, Tarning J, Imwong M, Jacob CG, Rasmussen C, Perin J, Ringwald P, Nyunt MM: Reduced susceptibility of Plasmodium falciparum to artesunate in southern Myanmar. PLoS One 2013, 8:e57689.

15. Malmberg M, Ngasala B, Ferreira PE, Larsson E, Jovel I, Hjalmarsson A, Petzold M, Premji Z, Gil JP, Bjorkman A, Martensson A: Temporal trends of molecular markers associated with artemether-lumefantrine tolerance/ resistance in Bagamoyo district. Tanzania. Malar J 2013, 12:103.

16. Hastings IM, Watkins WM: Intensity of malaria transmission and the evolution of drug resistance. Acta Trop 2005, 94:218-229.

17. Alifrangis M, Lemnge MM, Ronn AM, Segeja MD, Magesa SM, Khalil IF, Bygbjerg IC: Increasing prevalence of wildtypes in the dihydrofolate reductase gene of Plasmodium falciparum in an area with high levels of sulfadoxine/pyrimethamine resistance after introduction of treated bed nets. Am J Trop Med Hyg 2003, 69:238-243.

18. Mharakurwa S, Mutambu SL, Mudyiradima R, Chimbadzwa T, Chandiwana SK, Day KP: Association of house spraying with suppressed levels of drug resistance in Zimbabwe. Malar J 2004, 3:35.

19. Shah M, Kariuki S, Vanden Eng J, Blackstock AJ, Garner K, Gatei W, Gimnig JE, Lindblade K, Terlouw D, ter Kuile F, Hawley WA, Phillips-Howard P, Nahlen B, Walker E, Hamel MJ, Slutsker L, Shi YP: Effect of transmission reduction by insecticide-treated bednets (ITNs) on antimalarial drug resistance in western Kenya. PLoS One 2011, 6:e26746.

20. Hailemeskel E, Kassa M, Taddesse G, Mohammed H, Woyessa A, Tasew G, Sleshi M, Kebede A, Petros B: Prevalence of sulfadoxine-pyrimethamine resistance-associated mutations in dhfr and dhps genes of Plasmodium falciparum three years after SP withdrawal in Bahir Dar, Northwest Ethiopia. Acta Trop 2013, 128:636-641.

21. Ndiaye M, Faye B, Tine R, Ndiaye $J$, Lo A, Abiola A, Dieng Y, Ndiaye D, Hallett R, Alifrangis M, Gaye O: Assessment of the molecular marker of Plasmodium falciparum chloroquine resistance (Pfcrt) in Senegal after several years of chloroquine withdrawal. Am J Trop Med Hyg 2012, 87:640-645.

22. Mang'era CM, Mbai FN, Omedo IA, Mireji PO, Omar SA: Changes in genotypes of Plasmodium falciparum human malaria parasite following withdrawal of chloroquine in Tiwi, Kenya. Acta Trop 2012, 123:202-207.

23. Mita T, Kaneko A, Lum JK, Bwijo B, Takechi M, Zungu IL, Tsukahara T, Tanabe K, Kobayakawa T, Bjorkman A: Recovery of chloroquine sensitivity and low prevalence of the Plasmodium falciparum chloroquine resistance transporter gene mutation K76T following the discontinuance of chloroquine use in Malawi. Am J Trop Med Hyg 2003, 68:413-415.

24. Kublin JG, Cortese JF, Njunju EM, Mukadam RA, Wirima JJ, Kazembe PN, Djimde AA, Kouriba B, Taylor TE, Plowe CV: Reemergence of chloroquine-sensitive Plasmodium falciparum malaria after cessation of chloroquine use in Malawi. J Infect Dis 2003, 187:1870-1875.

25. Thaithong S, Suebsaeng L, Rooney W, Beale GH: Evidence of increased chloroquine sensitivity in Thai isolates of Plasmodium falciparum. Trans R Soc Trop Med Hyg 1988, 82:37-38.

26. de Almeida A, Arez AP, Cravo PV, do Rosario VE: Analysis of genetic mutations associated with anti-malarial drug resistance in Plasmodium falciparum from the Democratic Republic of East Timor. Malar J 2009, 8:59.

27. Frank M, Lehners N, Mayengue PI, Gabor J, Dal-Bianco M, Kombila DU, Ngoma GM, Supan C, Lell B, Ntoumi F, Grobusch MP, Dietz K, Kremsner PG: A thirteen-year analysis of Plasmodium falciparum populations reveals high conservation of the mutant pfcrt haplotype despite the withdrawal of chloroquine from national treatment guidelines in Gabon. Malar J 2011, 10:304

28. Kamugisha E, Bujila I, Lahdo M, Pello-Esso S, Minde M, Kongola G, Naiwumbwe $H$, Kiwuwa S, Kaddumukasa M, Kironde F, Swedberg G: Large differences in prevalence of Pfcrt and Pfmdr1 mutations between Mwanza, Tanzania and Iganga, Uganda-a reflection of differences in policies regarding withdrawal of chloroquine? Acta Trop 2012, 121:148-151.
29. Mwai L, Ochong E, Abdirahman A, Kiara SM, Ward S, Kokwaro G, Sasi P Marsh K, Borrmann S, Mackinnon M, Nzila A: Chloroquine resistance before and after its withdrawal in Kenya. Malar J 2009, 8:106

30. Mharakurwa S, Kumwenda T, Mkulama MA, Musapa M, Chishimba S, Shiff CJ, Sullivan DJ, Thuma PE, Liu K, Agre P: Malaria antifolate resistance with contrasting Plasmodium falciparum dihydrofolate reductase (DHFR) polymorphisms in humans and Anopheles mosquitoes. Proc Natl Acad Sci USA 2011, 108:18796-18801.

31. Djimde A, Doumbo OK, Cortese JF, Kayentao K, Doumbo S, Diourte Y, Dicko A, Su XZ, Nomura T, Fidock DA, Wellems TE, Plowe CV: A molecular marker for chloroquine-resistant falciparum malaria. $N$ Engl J Med 2001, 344:257-263.

32. Kent RJ, West AJ, Norris DE: Molecular differentiation of colonized human malaria vectors by $28 \mathrm{~S}$ ribosomal DNA polymorphisms. Am J Trop Med Hyg 2004, 71:514-517.

33. Musapa M, Kumwenda T, Mkulama M, Chishimba S, Norris DE, Thuma PE, Mharakurwa S: A simple Chelex protocol for DNA extraction from Anopheles spp. J Vis Exp 2013, 71. doi: 10.3791/3281

34. Kain KC, Lanar DE: Determination of genetic variation within Plasmodium falciparum by using enzymatically amplified DNA from filter paper disks impregnated with whole blood. J Clin Microbiol 1991, 29:1171-1174.

35. Djimde A, Doumbo OK, Steketee RW, Plowe CV: Application of a molecular marker for surveillance of chloroquine-resistant falciparum malaria. Lancet 2001, 358:890-891.

36. Temu EA, Kimani I, Tuno N, Kawada H, Minjas JN, Takagi M: Monitoring chloroquine resistance using Plasmodium falciparum parasites isolated from wild mosquitoes in Tanzania. Am J Trop Med Hyg 2006, 75:1182-1187.

37. Froberg G, Ferreira PE, Martensson A, Ali A, Bjorkman A, Gil JP: Assessing the cost-benefit effect of a Plasmodium falciparum drug resistance mutation on parasite growth in vitro. Antimicrob Agents Chemother 2013, 57:887-892.

38. Fisher N, Abd Majid R, Antoine T, Al-Helal M, Warman AJ, Johnson DJ, Lawrenson AS, Ranson H, O'Neill PM, Ward SA, Biagini GA: Cytochrome b mutation Y268S conferring atovaquone resistance phenotype in malaria parasite results in reduced parasite bc1 catalytic turnover and protein expression. J Biol Chem 2012, 287:9731-9741.

39. Babiker HA, Hastings IM, Swedberg G: Impaired fitness of drug-resistant malaria parasites: evidence and implication on drug-deployment policies. Expert Rev Anti Infect Ther 2009, 7:581-593.

40. Walliker $D$, Hunt $P$, Babiker $H$ : Fitness of drug-resistant malaria parasites. Acta Trop 2005, 94:251-259.

41. Ecker A, Lehane AM, Clain J, Fidock DA: PfCRT and its role in antimalarial drug resistance. Trends Parasitol 2012, 28:504-514.

42. Ord R, Alexander N, Dunyo S, Hallett R, Jawara M, Targett G, Drakeley CJ, Sutherland CJ: Seasonal carriage of pfcrt and pfmdr1 alleles in Gambian Plasmodium falciparum imply reduced fitness of chloroquine-resistant parasites. J Infect Dis 2007, 196:1613-1619.

43. Abraham EG, Pinto SB, Ghosh A, Vanlandingham DL, Budd A, Higgs S, Kafatos FC, Jacobs-Lorena M, Michel K: An immune-responsive serpin, SRPN6, mediates mosquito defense against malaria parasites Proc Natl Acad Sci USA 2005, 102:16327-16332

44. Hillyer JF, Barreau C, Vernick KD: Efficiency of salivary gland invasion by malaria sporozoites is controlled by rapid sporozoite destruction in the mosquito haemocoel. Int J Parasitol 2007, 37:673-681.

45. Boissiere A, Tchioffo MT, Bachar D, Abate L, Marie A, Nsango SE, Shahbazkia $\mathrm{HR}$, Awono-Ambene PH, Levashina EA, Christen R, Morlais I: Midgut microbiota of the malaria mosquito vector Anopheles gambiae and interactions with Plasmodium falciparum infection. PLoS Pathog 2012, 8:e1002742

46. Eappen AG, Smith RC, Jacobs-Lorena M: Enterobacter-activated mosquito immune responses to Plasmodium involve activation of SRPN6 in Anopheles stephensi. PLoS One 2013, 8:e62937.

47. Cirimotich CM, Dong Y, Clayton AM, Sandiford SL, Souza-Neto JA, Mulenga M, Dimopoulos G: Natural microbe-mediated refractoriness to Plasmodium infection in Anopheles gambiae. Science 2011, 332:855-858.

48. Kone A, van de Vegte-Bolmer M, Siebelink-Stoter R, van Gemert GJ, Dara A Niangaly H, Luty A, Doumbo OK, Sauerwein R, Djimde AA: Sulfadoxinepyrimethamine impairs Plasmodium falciparum gametocyte infectivity and Anopheles mosquito survival. Int J Parasitol 2010, 40:1221-1228.

49. A-Elbasit IE, Elbashir MI, Khalil IF, Alifrangis M, Giha HA: The efficacy of sulfadoxine-pyrimethamine alone and in combination with chloroquine 
for malaria treatment in rural Eastern Sudan: the interrelation between resistance, age and gametocytogenesis. Trop Med Int Health 2006, 11:604-612

50. Liu DQ, Liu RJ, Ren DX, Gao DQ, Zhang CY, Qui CP, Cai XZ, Ling CF, Song $\mathrm{AH}$, Tang X: Changes in the resistance of Plasmodium falciparum to chloroquine in Hainan, China. Bull World Health Organ 1995, 73:483-486.

51. Laufer MK, Takala-Harrison S, Dzinjalamala FK, Stine OC, Taylor TE, Plowe CV: Return of chloroquine-susceptible falciparum malaria in Malawi was a reexpansion of diverse susceptible parasites. J Infect Dis 2010, 202:801-808.

doi:10.1186/1475-2875-12-453

Cite this article as: Mharakurwa et al: Selection for chloroquine-sensitive Plasmodium falciparum by wild Anopheles arabiensis in Southern Zambia. Malaria Journal 2013 12:453.

\section{Submit your next manuscript to BioMed Central and take full advantage of:}

- Convenient online submission

- Thorough peer review

- No space constraints or color figure charges

- Immediate publication on acceptance

- Inclusion in PubMed, CAS, Scopus and Google Scholar

- Research which is freely available for redistribution 